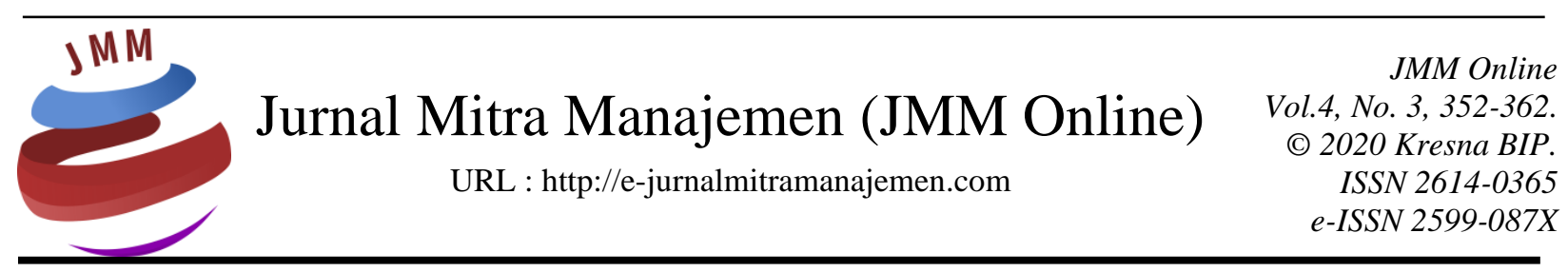

\title{
PENGARUH DISIPLIN KERJA TERHADAP KINERJA KARYAWAN (STUDI PADA PT INFOMEDIA SOLUSI HUMANIKA BANDUNG DIVISI INBOUND CALL CENTER)
}

\section{Cantika Afrizya Nugraha ${ }^{1)}$, Fetty Poerwita Sari ${ }^{2)}$ Universitas Telkom}

\section{INFORMASI ARTIKEL}

Dikirim : 06 Maret 2020

Revisi pertama : 20 Maret 2020

Diterima : 25 Maret 2020

Tersedia online : 30 Maret 2020

Kata Kunci : Disiplin Kerja, Kinerja Karyawan

Email : cantika.an@gmail.com ${ }^{1)}$, poerwitasary@gmail.com ${ }^{2}$

\section{ABSTRAK}

Penelitian ini dilakukan untuk mengetahui disiplin kerja karyawan, kinerja karyawan dan pengaruh disiplin kerja terhadap kinerja karyawan. Penelitian ini menggunakan metode kuantitatif. Metode pengumpulan data dilakukan dengan penyebaran kuesioner kepada 200 karyawan dan pengambilan sampel dengan sample jenuh. Kuesioner yang digunakan terdiri dari 27 item pernyataan. Teknik analisis data menggunakan analisis deskriptif, analisis linier sederhana, dan uji asumsi klasik. Hasil uji regresi menunjukan bahwa disiplin kerja berpengaruh signifikan positif terhadap kinerja karyawan PT Infomedia Solusi Humanika Bandung Divisi Inbound Call Center. Disiplin kerja berpengaruh sebesar 44,50\% terhadap kinerja karyawan PT Infomedia Solusi Humanika Bandung Divisi Inbound Call Center, sisanya yaitu sebesar 55,50\% dipengaruhi oleh variabel lain yang tidak diteliti dalam penelitian ini. 


\section{PENDAHULUAN \\ Latar Belakang}

Setiap perusahaan yang didirikan pasti memiliki tujuan, salah satunya yaitu berkembang dengan pesat dan memperoleh profit yang tinggi. Dalam mencapai tujuan tersebut perusahaan membutuhkan sumber daya manusia yang potensial pada pengerjaan tugas dan pengawasan perusahaan. Menurut Wicaksono (2016) pada era globalisasi, persaingan pelaku bisnis akan semakin tajam, perusahaan harus mampu merubah setiap tantangan menjadi sebuah peluang, dalam mencapai hal tersebut perusahaan harus mengelola sumber daya manusia supaya menghasilkan kinerja yang baik.

Kinerja dipengaruhi oleh beberapa faktor menurut Setyawan (2018) yaitu penghargaan karyawan, kepuasan karyawan, perilaku karyawan, gaya kepemimpinan. Selanjutnya penelitian oleh Dwipayana dan Dewi (2016) faktor-faktor yang mempengaruhi kinerja karyawan yaitu kepemimpinan, motivasi, kompensasi, komunikasi. Faktor-faktor seperti motivasi, kompetensi, kepemimpin juga dapat mempengaruhi kinerja karyawan di suatu perusahaan (Hasriana, 2017). Menurut Anggarini (2018) Kinerja karyawan dapat dipengaruhi oleh gaya kepemimpinan situasional, motivasi, dan disiplin kerja. Purba et al (2019) menyebutkan bahwa faktor seperti kepuasan kerja, motivasi kerja dan disiplin kerja secara parsial berpengaruh positif terhadap kinerja karyawan. Jika disiplin kerja meningkat maka kinerja karyawan juga akan meningkat begitupun sebaliknya. Disiplin kerja yang baik akan mempengaruhi seseorang dalam mencapai target pekerjaannya.

PT Infomedia Solusi Humanika Bandung Divisi Inbound Call Center merupakan divisi yang menangani panggilan masuk dari pelanggannya sehingga karyawan harus memiliki disiplin kerja yang baik seperti ketepatan dalam melayani pelanggan, waktu panggilan, informasi produk dan lain sebagainya. Maka dari itu kinerja pada divisi inbound call center juga perlu diperhatikan karena pada divisi ini yang berhadapan langsung dengan konsumen, puas tidaknya pelanggan dapat diketahui oleh divisi inbound call center. Inti Pembahasan dari penelitian ini adalah untuk mengetahui pengaruh disiplin kerja terhadap kinerja karyawan PT Infomedia Solusi Humanika Bandung Divisi Inbound Call Center.

\section{Rumusan Masalah}

Berdasarkan latar belakang, maka muncul permasalahan yang dirumuskan sebagai berikut:

1. Bagaimana disiplin kerja di PT. Infomedia Solusi Humanika Bandung Divisi Inbound Call Center?

2. Bagaimana kinerja karyawan di PT. Infomedia Solusi Humanika Bandung Divisi Inbound Call Center?

3. Apakah disiplin kerja memiliki pengaruh positif dan signifikan terhadap kinerja karyawan di PT. Infomedia Solusi Humanika Bandung Divisi Inbound Call Center? 


\section{Tujuan Penelitian}

Berdasarkan perumusan masalah tersebut, maka didapatkan tujuan penelitian sebagai berikut:

1. Untuk mengetahui disiplin kerja yang ada pada PT. Infomedia Solusi Humanika Bandung Divisi Inbound Call Center

2. Untuk mengetahui kinerja karyawan pada PT. Infomedia Solusi Humanika Bandung Divisi Inbound Call Center

3. Untuk mengetahui apakah disiplin kerja memiliki perngaruh positif dan signifikan terhadap kinerja karyawan pada PT. Infomedia Solusi Humanika Bandung Divisi Inbound Call Center

\section{KAJIAN PUSTAKA \\ Disiplin Kerja}

Menurut Darotjat (2015:93) menjelaskan bahwa disiplin berasal dari bahasa latin disciplina yang berarti latihan kesopanan dan latihan kerohanian serta latihan pengembangan tabiat. Sutrisno (2016:86) yang dimaksud dengan disiplin kerja adalah kesediaan dan kerelaan seseorang untuk mematuhi dan mentaati norma-norma peraturan. Selanjutya menurut Hasibuan (2017:193) kedisiplinan adalah kesadaran atau kesediaan individu untuk mamatuhi segala peraturan yang berlaku di sebuah organisasi. Menurut Sutrisno (2016:89) disiplin adalah prilaku seseorang yang sesuai dengan peraturan, prosedur kerja yang ada atau disiplin adalah sikap, tingkah laku, dan perbuatan yang sesuai dengan peraturan dari organisasi baik tertulis maupun tidak tertulis.

Sutrisno (2016:89), mengatakan bahwa disiplin kerja dapat dilihat sebagai sesuatu yang besar manfaatnya, baik bagi kepentingan organisasi maupun bagi para karyawan. Manfaat disiplin kerja bagi perusahaan yaitu menjamin terpeliharanya tata tertib dan kelancaran pelaksanaan tugas, sehingga di peroleh hasil yang optimal, kemudian manfaat disiplin kerja bagi karyawan yaitu menjamin memberikan kenyamanan kepada karyawan sehingga akan menambah semangat kerja dalam melaksanakan tugasnya. Dengan demikian, karyawan dapat melaksanakan tugas dengan penuh kesadaran serta dapat mengembangkan tenaga dan pikirannya semaksimal mungkin demi terwujudnya tujuan organisasi. Menurut Hamali (2017:214) disiplin adalah suatu kekuatan yang berkembang di dalam tubuh karyawan dan menyebabkan karyawan dapat menyesuaikan diri dengan sukarela pada keputusan peraturan, dan nilai-nilai tinggi dari pekerjaan danperilaku. Sinambela (2016:243) menyatakan bahwa disiplin kerja bermanfaat untuk memastikan bahwa perilakuperilaku pegawai konsisten dengan aturan-aturan yang telah di tetapkan organisasi. Berbagai aturan yang telah di tetapkan organisasi adalah tuntutan untuk mencapai tujuan organisasi yang di tetapkan

Penelitian ini menggunakan dimensi dari Hasibuan (2017:194) yang memiliki delapan dimensi yaitu:

1. Tujuan dan kemampuan

2. Teladan pimpinan

3. Balas jasa

4. Keadilan 

5. Waskat
6. Sanksi
7. Ketegasan
8. Hubungan kemanusiaan.

\section{Kinerja Karyawan}

Sedarmayanti (2016:260) menjelaskan bahwa kinerja adalah hasil kerja yang dapat dicapai oleh seseorag atau sekelompok orang dalam suatu organisasi, sesuai dengan wewenang dan tanggung jawab masing-masing dalam rangka upaya mencapai tujuan organisasi bersangkutan secara legal, tidak melanggar hukum dan sesuai dengan moral maupun etika. Kinerja pegawai menurut Edison et al (2017:188) adalah hasil dari suatu proses yang mengacu dan diukur selama periode waktu tertentu berdasarkan ketentuan atau kesepakatan yang telah ditetapkan sebelumnya. Selanjutnya menurut Kasmir (2016:182) kinerja adalah hasil kerja dari pelaksanaan tugas dan tanggung jawab yang dapat dicapai oleh para karyawan dalam periode tertentu.

Kinerja pegawai tidak terlepas dari faktor-faktor yang mempengaruhinya, menurut Wirawan (2015:21) yang mempengaruhi kinerja pegawai adalah kondisi internal individu, faktor lingkungan internal organisasi, dan faktor ekstenal organisasi. Selanjutnya menurut Mangkunegara (2017:67) adalah faktor kemampuan dan faktor motivasi. Secara psikologis kemampuan pegawai terdiri dari kemampuan potensi (IQ) dan kemampuan realiti (skill). Artinya, pegawai yang memiliki IQ di atas rata-rata (IQ 110-120) dengan pendidikan yang memadai untuk jabatannya dan terampil dalam mengerjakan pekerjaan sehari-hari, maka ia akan lebih mudah. Berdasarkan penelitian terdahulu menjelaskan bahwa faktor-faktor yang mempengaruhi kinerja karyawan menurut Setyawan (2018) yaitu penghargaan karyawan, kepuasan karyawan, perilaku karyawan, gaya kepemimpinan. Selanjutnya penelitian oleh Dwipayana dan Dewi (2016) faktor-faktor yang mempengaruhi kinerja karyawan yaitu kepemimpinan, motivasi, kompensasi, komunikasi. Faktor- faktor seperti motivasi, kompetensi, kepemimpin juga dapat mempengaruhi kinerja karyawan di suatu perusahaan (Hasriana, 2017).

Penelitian ini menggunakan dimensi dari Bernardin dalam Sudarmanto (2018:12) yang memiliki enam dimensi yaitu:
1. Quality
2. Quantity
3. Timeliness
4. Cost-effectiveness
5. Need for supervision
6. Interpersonal impact

\section{Hubungan Disiplin Kerja Dengan Kinerja Karyawan}

Penelitian yang menggunakan disiplin kerja sebagai variabel independen dan kinerja karyawan sebagai variabel dependen sebelumnya telah cukup banyak dilakukan. Seperti penelitian yang dilakukan oleh Mailiana (2016) di Dinas Pengelolaan Pasar Kota Banjarmasin dengan hasil disiplin kerja memberikan pengaruh yang signifikan dan positif terhadap kinerja kerja karyawan. Selanjutnya penelitian di 
Cipta Hotel Pancoran Jakarta oleh Pramularso (2017) dengan hasil disiplin kerja berpengaruh positif dan signifikan terhadap kinerja karyawan.

Berdasarkan penelitian dari Suci dan idrus (2015) di PT. Merpati Nusantara bahwa disiplin kerja secara parsial memiliki pengaruh terhadap kinerja karyawan pemeliharaan fasilitas PT Merpati Nusantara Airlines (Persero) Surabaya. Penelitian lain yang mengukur disiplin kerja terhadap kinerja karyawan dilakukan oleh Jeffrey dan Soleman (2017) pada Lembaga Ketahanan Nasional Indonesia yang menyatakan bahwa disiplin kerja berpengaruh secara simultan terhadap kinerja karyawan.

Berdasarkan penjelasan diatas maka kerangka pemikiran dalam penelitian ini adalah sebagai berikut:

\section{Gambar 1. Kerangka Pemikiran}

\begin{tabular}{|l|l|}
\hline \multicolumn{1}{|c|}{ Disiplin Kerja (X) } & \multicolumn{1}{c|}{ Kinerja (Y) } \\
1. Tujuan dan Kemampuan & \\
2. Teladan Pimpinan & 1. Quality \\
3. Balas Jasa & 2. Quantity \\
4. Keadilan & 3. Timeliness \\
5. Waskat & 4. Cost-Effectiveness \\
6. Sanksi Hukuman & 5. Need for supervision \\
7. Ketegasan & 6. Interpersonal impact \\
8. Hubungan Kemanusiaan & \\
Sumber: Hasibuan (2017:194) & Sumber: Bernardin dalam \\
& Sudarmanto (2018:12) \\
& \\
\end{tabular}

Sumber: Hasil Olahan Penulis, 2019

Berdasarkan uraian diatas maka dapat disimpulkan bahwa disiplin kerja memiliki pengaruh positif terhadap kinerja karyawan. Artinya, apabila disiplin semakin meningkat maka kinerja karyawan juga akan semakin meningkat, maka penulis menentukan hipotesis dalam penelitian ini yaitu "Disiplin Kerja memiliki pengaruh positif dan signifikan terhadap Kinerja Karyawan pada PT Infomedia Solusi Humanika Bandung divisi inbound call center"

\section{METODE PENELITIAN Jenis Penelitian}

Metode penelitian yang digunakan penelitian ini adalah metode kuantitatif, yaitu penelitian dengan filsafat positivism dengan menggunakan instrument penelitian dan untuk pengujian hipotesis. Berdasarkan tujuan yaitu kausal artinya peneliti ingin mengetahui hubungan sebab-akibat yang terjadi antar variabel. Berdasarkan 
keterlibatan penulis, penulis tidak mengintervensi data dengan menggunakan unit analisis individu. Berdasarkan waktu pelaksanaan, penelitian ini termasuk dalam crosssection yaitu pengambilan data dilakukan dalam satu periode waktu tertentu.

\section{Variabel Penelitian}

Variabel dalam penelitian ini terdiri dari variabel bebas (independent variable) yaitu disiplin kerja (X) dan variabel bebas (dependent variable) yaitu kinerja karyawan (Y)

\section{Tempat dan Waktu Penelitian}

Penelitian ini bertempat di PT Infomedia Solusi Humanika, Jl. Terusan Buah Batu No.33, Batununggal, Kec. Bandung Kidul, Kota Bandung, Jawa Barat 40266. Penelitian ini dilaksanakan pada bulan Oktober 2019 hingga Februari 2020.

\section{Uji Validitas dan Reabilitas}

Uji Validitas adalah untuk mengetahui tingkat kevalidan dari instrumen kuesioner yang digunakan dalam pengumpulan data. Uji validitas ini dilakukan untuk mengetahui apakah item-item yang tersaji dalam kuesioner benar-benar mampu mengungkapkan dengan pasti apa yang akan diteliti. Syarat minimum untuk dianggap valid adalah nilai $r>0,361$. Hasil uji validitas untuk semua pernyataan lebih dari 0,361 maka dinyatakan semua item dapat digunakan sebagai instrument penelitian.

Penelitian ini menggunakan uji reliabilitas dengan menggunakan Cronbach's Alpha. Disiplin kerja memperoleh hasil sebesar 0,754 yang artinya nilai tersebut lebih besar dari Cronbach's Alpha yaitu 06,00. Sedangkan kinerja karyawan memperoleh hasil 0,762 yang artinya nilai tersebut lebih besar dari Cronbach's Alpha yaitu 06,00. Hasil uji reabilitas kedua variabel berada dalam derajat keadan luar biasa bagus, sehingga layak digunakan sebagai instrumen penelitian ini.

\section{Teknik Pengumpulan Data}

Data primer dalam penelitian ini diperoleh melalui penyebaran kuesioner, wawancara, dan pengamatan langsung di lapangan. Data sekunder dalam penelitian ini berupa dokumen perusahaan dan literatur di perpustakaan. Pengukuran kedua variabel dalam penelitian menggunakan 17 item pernyataan terkait disiplin kerja dan 10 item pernyataan terkait kinerja karyawan dengan menggunakan sample jenuh.

\section{Teknik Analisis Data}

Penelitian ini menggunakan teknik analisis data yaitu analisis deskriptif, analisis regresi linear sederhana dengan uji asumsi klasik yaitu uji normalitas, uji heteroskedastisitas, dan uji linear. Dalam penelitian ini analisis linear sederhana digunakan untuk mengukur arah pengaruh disiplin kerja terhadap kinerja karyawan. Penelitian ini juga menggunakan uji $\mathrm{t}$ sebagai uji hipetesis dan uji koefisien determinasi untuk mengetahui seberapa besar pengaruh disiplin terhadap kinerja karyawan. 


\section{HASIL PENELITIAN DAN PEMBAHASAN \\ Hasil Penelitian \\ Uji Normalitas}

Uji normalitas dilakukan untuk melihat apakah data memiliki distribusi yang normal atau tidak. Uji normalitas dalam penelitian ini dilakukan melalui uji statistik non-parametrik, Kolmogorov-Smirnov, dimana data berdistribusi normal akan memiliki nilai Asymp.sig > nilai signifikansi $(0,05)$. Berikut hasil uji normalitas :

Tabel 1. Hasil Uji Normalitas-Kolmogorov Smirnov

\begin{tabular}{|l|l|}
\hline \multicolumn{2}{|c|}{ One-Sample Kolmogorov-Smirnov Test } \\
\hline Kolmogorov-Smirnov $Z$ & .883 \\
\hline Asymp. Sig. (2-tailed) & .417 \\
\hline
\end{tabular}

Sumber: Hasil Penelitian, diolah (2020)

Berdasarkan tabel 1. Maka dapat disimpulkan bahwa data telah berdistribusi normal karena nilai Asymp. Sig. (2-tailed) yaitu 0,417 lebih besar dari 0,05.

\section{Uji Heteroskedastisitas}

Uji heteroskedastisitas dalam penelitian ini dilakukan dengan menggunakan uji Glejser dengan ketentukan bahwa semua variabel terbebas dari heteroskedastisitas jika memiliki nilai sig lebih dari nilai alpha (5\%). Hasil uji Glejser dapat dilihat pada tabel sebagai berikut:

Tabel 2. Hasil Uji Glejser
\begin{tabular}{|l|l|c|}
\hline \multicolumn{2}{|l|}{ Coefficients $^{\mathbf{a}}$} \\
\hline \multicolumn{2}{|c|}{ Model } & Sig. \\
\hline 1 & (Constant) & .107 \\
\cline { 2 - 3 } & Disiplin Kerja & .592 \\
\hline
\end{tabular}

Sumber: Hasil Penelitian, diolah (2020)

Dapat dilihat nilai signifikansi variabel disiplin kerja yaitu sebesar 0,592 lebih besar dari nilai alpha 0,05 . Sehingga dapat diambil kesimpulan bahwa model regresi terbebas dari heteroskedastisitas.

\section{Uji Linearitas}

Uji linearitas dalam penelitian ini dilakukan agar dapat diketahui adanya hubungan yang linear diantara variabel disiplin kerja dan variabel kinerja karyawan. Kedua variabel memiliki hubungan yang linear apabila nilai signifikansi (Linearity) kurang dari 0,05. Hasil uji linearitas dapat dilihat sebagai berikut:

Tabel 3. Uji Linearitas

\begin{tabular}{|c|c|c|c|}
\hline \multicolumn{4}{|c|}{ ANOVA Table } \\
\hline & & & Sig. \\
\hline \multirow{2}{*}{$\begin{array}{l}\text { Kinerja } \\
\text { Disiplin } \\
\text { Kerja }\end{array}$} & \multirow{2}{*}{$\begin{array}{l}\text { Between } \\
\text { Groups }\end{array}$} & (Combined) & .000 \\
\hline & & Linearity & .000 \\
\hline
\end{tabular}

Dapat dilihat bahwa nilai signifikansi Linearity yaitu sebesar 0,000 lebih kecil atau kurang dari 0,05. Berdasarkan teori dan hasil SPSS, maka penulis mengambil 
kesimpulan bahwa terdapat hubungan yang linear diantara variabel independen disiplin kerja dan variabel dependen kinerja karyawan.

\section{Analisis Regresi Linear Sederhana}

Penelitian ini menggunakan model analisis regresi linear sederhana dengan hasil sebagai berikut:

Tabel 4. Uji Koefisien Regresi

\begin{tabular}{|l|l|l|l|}
\hline \multicolumn{3}{|l|}{ Coefficients } \\
\hline Model & B & Sig. \\
\hline 1 & (Constant) & .948 & .000 \\
\cline { 2 - 4 } & $\begin{array}{l}\text { Disiplin } \\
\text { Kerja }\end{array}$ & .711 & .000 \\
\hline
\end{tabular}

Sumber: Hasil Penelitian, diolah (2020)

Berdasarkan tabel 4. Didapatkan persamaan sebagai berikut:

$$
\mathbf{Y}=\mathbf{0 , 9 4 8 + 0 , 7 1 1 X}
$$

Tanda koefisien regresi variabel independen menunjukkan arah hubungan dari variabel yang bersangkutan dengan Kinerja (Y). Koefisien regresi untuk variabel independen bernilai positif, menunjukkan adanya hubungan yang searah atau positif antara Disiplin Kerja (X) dengan Kinerja (Y).

Nilai konstanta (a) sebesar 0,948 menunjukkan bahwa ketika $\mathrm{X}$ atau nilai dari variabel independen yang dalam penelitian ini ialah disiplin kerja bernilai nol, maka nilai Y atau nilai kinerja karyawan bernilai 0,948. Nilai koefisien regresi (b) sebesar 0,711 memiliki arti bahwa setiap adanya peningkatan dalam variabel $\mathrm{X}$ atau variabel disiplin kerja sebesar 1 satuan, maka akan meningkatkan variabel $\mathrm{Y}$ atau kinerja karyawan sebesar 0,711 .

\section{Uji Koefisien Determinasi}

Uji koefisien determinasi digunakan untuk mengetahui seberapa besar disiplin kerja dapat menjelaskan kinerja karyawan di PT Infomedia Solusi Humanika Bandung Divisi Inbound Call Center. Nilai koefisien determinasi atau $\mathrm{R}$ Square $\left(\mathrm{R}^{2}\right)$ yang diperoleh dalam penelitian ini dapat dilihat pada tabel 5. Sebagai berikut:

\section{Tabel 5. Uji Koefisien Determinasi}

\begin{tabular}{|l|l|l|}
\hline \multicolumn{3}{|c|}{ Model Summary } \\
\hline Model & $\mathrm{R}$ & $\begin{array}{l}\mathrm{R} \\
\text { Square }\end{array}$ \\
\hline 1 & $.667^{\mathrm{a}}$ & .445 \\
\hline
\end{tabular}

Sumber: Hasil Penelitian, diolah (2020)

Dapat dilihat pada tabel 5. nilai koefisien determinasi yang merupakan hasil kuadrat nilai $\mathrm{R}$ ialah sebesar 0,445 atau jika dalam persentase yaitu sebesar $44,50 \%$. Hal tersebut menunjukkan bahwa sebesar $44,50 \%$ kinerja karyawan dapat dijelaskan dengan menggunakan variabel disiplin kerja, sedangkan sebesar 55,50\% Kinerja Karyawan PT Infomedia Solusi Humanika Bandung Divisi Inbound Call Center dijelaskan oleh faktor lain atau dapat dikatakan pula bahwa disiplin kerja dipengaruhi oleh variabel lainnya yang tidak diteliti. 


\section{Uji Hipotesis}

Tujuan yang ingin dicapai dalam penelitian ini salah satunya ialah untuk mengetahui apakah disiplin kerja sebagai variabel independen memiliki pengaruh signifikan terhadap kinerja karyawan PT Infomedia Solusi Humanika Bandung Divisi inbound Call Center sebagai variabel dependen. Dalam mencapai tujuan tersebut penulis menggunakan uji t dengan membuat hipotesis yaitu:

H0 : Disiplin kerja tidak memiliki pengaruh positif dan signifikan terhadap kinerja karyawan PT Infomedia Solusi Humanika Bandung Divisi Inbound Call Center.

H1 : Disiplin kerja memiliki pengaruh positif dan signifikan terhadap kinerja karyawan PT Infomedia Solusi Humanika Bandung Divisi Inbound Call Center.

Selanjutnya menghitung nilai t tabel yang dapat ditentukan dengan melihat $\alpha$ dan DF sebagai berikut:

$$
\text { Nilai } \alpha=5 \%: 2=2,5 \% \text { (uji } 2 \text { sisi) }
$$

Nilai DF dengan rumus: $\mathrm{DF}=$ jumlah data -2

Dengan jumlah data sebanyak 200 maka nilai DF yang diperoleh ialah198. Maka t tabel yang didapatkan ialah sebesar 1,97202. Selanjutnya ialah menghitung nilai $\mathrm{t}$ hitung dengan menggunakan bantuan aplikasi SPSS. Nilai $\mathrm{t}$ hitung telah didapatkan dan dapat dilihat pada tabel 6. sebagai berikut:

Tabel 6. Uji Koefisien Determinasi

\begin{tabular}{|l|l|l|}
\hline \multicolumn{2}{|l|}{ Coefficients $^{\mathbf{a}}$} & $\mathrm{t}$ \\
\hline Model & (Constant) & 5.212 \\
\hline 1 & $\begin{array}{l}\text { Disiplin } \\
\text { Kerja }\end{array}$ & 12.594 \\
\hline
\end{tabular}

Sumber: Hasil Penelitian, diolah (2020)

Berdasarkan Tabel 6. di atas, diperoleh nilai t hitung sebesar 12,594 dan nilai signifikansi sebesar 0,000. Keputusan mengenai hipotesis yang telah dipaparkan diatas dapat diambil dengan melihat kriteria pengambilan keputusan sebagai berikut:

a. Jika t hitung < t tabel maka $\mathrm{H} 0$ diterima dan $\mathrm{H} 1$ ditolak.

b. Jika t hitung > t tabel maka $\mathrm{H} 0$ ditolak dan $\mathrm{H} 1$ diterima.

Dalam Penelitian ini diperoleh t hitung ialah sebesar 12,594 lebih besar dari t tabel sebesar 1,97331 maka keputusan yang diambil ialah H0 ditolak dan H1 diterima. Dari pengambilan keputusan tersebut dapat disimpulkan bahwa disiplin kerja memiliki pengaruh positif dan signifikan terhadap kinerja karyawan.

\section{KESIMPULAN DAN SARAN \\ Kesimpulan}

Berdasarkan hasil pengujian yang diperoleh dari instrument penelitian yaitu kuesioner terkait dengan disiplin kerja mendapatkan persentase sebesar 76,13\% yang termasuk dalam kategori tinggi. Artinya disiplin kerja pada PT Infomedia Solusi Humanika Bandung Divisi Inbound Call Center sudah berjalan dengan baik. Selanjutnya, untuk kuesioner terkait kinerja karyawan mendapatkan persentase sebersar 76,70\%. Artinya, kinerja karyawan PT Infomedia Solusi Humanika Bandung Divisi Inbound Call Center sudah berjalan sesuai dengan yang diharapkan perusahaan. 


\section{Saran}

Berdasarkan hasil pembahasan dan kesimpulan yang telah diuraikan diatas penulis mengajukan saran pada PT Infomedia Solusi Humanika Bandung Divisi Inbound Call Center untuk memerhatikan pentingnya disiplin kerja pada kinerja karyawan, sosialisasi dan pengawasan disiplin karyawan diperlukan untuk dilakukan oleh setiap supervisor agar disiplin itu sendiri dapat meningkat. Menimbang bahwa peningkatan disiplin kerja akan berdampak pada peningkatan kinerja karyawan.

\section{DAFTAR PUSTAKA}

Anggarini, L. N. 2018. Analisis Faktor-Faktor YYang Mempengaruhi Kinerja Pegawai Perum Bulog Kantor Pusat. Jurnal EKSEKUTIF, 15(1), 260-280.

Darotjat, T. A. 2015. Pentingnya Budaya Kerja Tinggi dan Kuat Absolute. Bandung: P.T Refika Aditama.

Dwipayana, \& Dewi, S. 2016. Analisis Faktor-Faktor Yang Mempengaruhi Kinerja Pegawai Pada Pt Karang Bali Asli Tur. E-Jurnal Manajemen Unud, 5(3), 15421571.

Edison, E., Anwar, Y., \& Komariyah, I. 2017. Manajemen Sumber Daya Manusia. Bandung: Alfabeta.

Hamali, A. 2017. Pemahaman Manajemen Sumber Daya Manusia. Yogyakarta: CAPS.

Hasibuan, M. 2017. Manajemen Sumber Daya Manusia. Edisi Revisi. Jakarta: Bumi Aksara.

Hasriana. 2017. Analisis Faktor-Faktor yang Mempengaruhi Kinerja Pegawai Pada Kantor Distrik Navigasi Kelas I Makassar. Journal Mirai Management, 2(2), 270-282.

Jeffrey, I., \& Soleman, M. 2017. The effect of work discipline, achievement motivation and career path toward employee performance of The National Resilience Institute of The Republic of Indonesia. International Journal of Application or Innovation Engineering and Management (IJAEM), 6(8), 106-113.

Mailiana. 2016. Pengaruh Disiplin Kerja terhadap Kinerja Pegawai Dinas Pengelolaan Pasar Kota Banjarmasin. Jurnal Ekonomi Manajemen, 10(1), 123133.

Mangkunegara, P. A. 2017. Manajemen Sumber Daya Manusia Perusahaan. Bandung: Remaja Rosdakarya.

Pramularso, E. Y. 2017. Pengaruh Disiplin Kerja Terhadap Kinerja Karyawan Cipta Hotel Pancoran Jakarta Selatan. Jurnal Sekretari dan Manajemen, 1(2), 171178.

Purba, D. C., Lengkong, V., \& Loindong, S. 2019. Analisis Pengaruh Kepuasan Kerja, Motivasi Kerja Dan Disiplin Kerja Terhadap Kinerja Karyawan Pada Perusahaan Umum Percetakan Negara Republik Indonesia Cabang Manado. Jurnal EMBA, 7(1), 841-850.

Sedarmayanti. 2016. Manajemen Sumber Daya Manusia. Jakarta: Refika Aditama.

Setyawan, A. 2018. Analisis Faktor-Faktor yang Mempengaruhi Kinerja Karyawan (Studi Kasus Pada Tiga Perusahaan Fabrikasi Lepas Pantai di Batam dan Karimun). Journal of Accounting \& Management Innovation, 2(1), 67-89. 
Sinambela, L. P. 2016. Manajemen Sumber Daya Manusia. Jakarta: Bumi Aksara.

Suci, R. P., \& Idrus, M. S. 2015. The Influence of Employee Training and Discipline Work against Employee Performance PT. Merpati Nusantara Airlines (Persero). Review od European Studies, 7(11), 7-14.

Sudarmanto. 2018. Kinerja dan Pengembangan Kompetensi SDM (cetakan keempat). Yogyakarta: Pustaka Pelajar

Sutrisno, E. 2016. Manajemen Sumber Daya Manusia. Cetakan ke-9. Jakarta: Kencana Prenada Media Group.

Wicaksono, Y. S. 2016. Pengaruh Pelatihan dan Pengembangan Sumber Daya Manusia dalam Rangka Meningkatkan Semangat Kerja dan Kinerja Karyawan Studi di SKM Unit V PT. Gudang Garam,Tbk Kediri. Jurnal Bisnis dan Manajemen, 3(1), 31-39.

Wirawan. 2015. Manajemen Sumber Daya Manusia Indonesia. Jakarta: PT Raja Grafindo Persada. 